\title{
Knowledge and Practice of Assessment: Empirical Evidence from Early Childhood Teachers in the Kumasi Metropolis, Ghana
}

\author{
S. Oppong Frimpong, and D. Osei
}

\begin{abstract}
Sound assessment fosters learning, improves teaching, and provides information about what has been done or achieved by learners. Children cannot develop without them being assessed. However, information available to the researchers suggests that researches is done or are not done specifically at the early childhood level. This sequential explanatory mixed method was used to examine knowledge and assessment practices in some selected ECE centres in the Kumasi Metropolis. Two hundred and forty-two trained early childhood teachers were selected using table of random numbers and purposive sampling procedures. Self-developed questionnaire and a structured interview were used for data collection. The findings show that most of the participants had some level of understanding on assessment practices. It was found that, the majority of the teachers used assessment tools such as class exercise, portfolio building, in assessing their children. It was further found that most of the teachers had some level of experiences as they use the assessment tools, although they couldn't use multiple tools in their assessment. To maintain and improve the teachers' level of understanding on assessment practice, it is recommended that refresher courses on modern trends of assessment should be frequently organised to keep and maintain the knowledge base and skills of the teachers in assessment practices. It is also recommended that teachers should be sensitized on regular basis on the importance of their assessment practices to effectively practicalize the assessment done on pupils.
\end{abstract}

Index Terms-Assessment, Assessment Practices, knowledge, Early Childhood Centers, Empirical Evidence

\section{INTRODUCTION}

Assessment which is central to teaching and learning has become a critical component of education in today's policy development. Assessment is considered to be the evaluation on students' overall performance and generating assumptions regarding their learning [1]. Assessment includes collecting a wide range of information on aspects of learning such as the child's growth and self-esteem, interpersonal and intrapersonal behaviour, and the acquisition of a wide range of knowledge, skills, attitudes and values [2], [3]. It measures the quality or achievement in tasks such as tests, projects, reports and examinations.

Assessment of children in education plays a critical role to the progress of pupils in the Early Childhood Education (ECE) provision. Children cannot develop without being assessed. For a child to know his/her level of development,

Published on January 26, 2021.

S. Oppong Frimpong, Department of Early Childhood Education,

University of Education, Winneba, Ghana

(corresponding e-mail: sofrimpong ${ }^{\circledR}$ uew.edu.gh) he/she needs to be assessed. Assessment enables the child to improve on his/her level of attainment or development in an educational setting.

Assessment of early childhood pupils is very critical because effective teaching and learning decisions are based on the ability of teachers to understand the pupils and to match actions with accurate assessments results [4]. This clearly suggests that assessment has and should become a critical component of education in today's educational practice. Early childhood teachers are the key drivers and implementers of education process. Their instructional and assessment practices are means by which the education system is enhanced and defined [5].

Assessment knowledge elicits information and skills on how to align assessment with instructional goals. Further, teachers must know that there are multiple sources of evidence on student learning. Heritage [6] suggests four specific skills defined as pedagogical knowledge for practicing assessment teachers to be able to do. These are: creating the conditions for the formative practice, using student self-assessment, being able to interpret evidence of student learning and matching instruction to the gap.

Assessment in early childhood education is not a new practice in Ghana. Early childhood experts use a range of assessment tools to identify children's interactions, conversations, ideas and expressions in order to better understand each child's strengths, abilities and interests. Children are sometimes very difficult to accurately assess [7]. Thus, clear guidelines regarding the nature, functions and uses of early childhood assessment, including assessment formats that are appropriate for use in culturally and linguistically diverse communities must be created to help in establishing a developmentally appropriate assessment practices in preschools in Ghana. This requires effective personnel and tools to assess children's learning and identify their needs [8]. Implicit to all these is the teacher's level of understanding about assessment practices and therefore the tools they use in assessing their learners and their experiences as they use the tools.

\section{A. ECE Teachers' Level of Understanding about Assessment Practices}

Researchers have attempted to investigate teachers' perceptions of assessment in many different ways. Chester and Quilter [9] and Rahman [10] observed that studying teachers' perceptions of assessment is important in the sense

D. Osei, Department of Early Childhood Education, University of Education Winneba, Ghana

(e-mail: oseidorigen@gmail.com) 
that it provides an indication of how different forms of assessment are being used or misused and what could be done to improve the situation. More critical also is the fact that perceptions affect behaviour [11]. This behaviour includes the assessment tools the teacher will use. Therefore, some researchers have simply concluded that because of the complexity attached to the term "teacher beliefs", it cannot be defined easily [12]. However, it is unclear according to literature whether teachers' beliefs influence instructional behavior and their assessment practices [13]. On the contrary, [13] asserted that, what is clear in scholastic work is that teacher beliefs are robust, resistant to change, serve as filters for new knowledge, and act as barriers to changes in teaching practices. Furthermore, teachers' beliefs can either facilitate or inhibit curriculum reform, including assessment practices [13]. This implies that teachers' beliefs through their perception play a key role in determining how they will pursue their assessment practices in the ECE classroom [14], [15].

\section{B. Assessment Tools}

In the educational setting, assessment can be carried out using different tools and methods. These may include observation, anecdotal records, check list, rating scales and rubrics, conferences and portfolios.

Observation is an informal assessment technique of watching students to identify strengths and weaknesses, patterns of behaviour, and cognitive strategies. Anecdotal records, refers to a concise, objective narratives about an incident or person and a checklist is, any record that denotes the presence or absence of an attribute and is used to record the incidence of specific behaviours in a given circumstance. At the ECE, other tools are rating scales which are similar to checklists but differ in that they allow the observer to judge performance along a continuum rather than just a dichotomy [7], [16]. Rubrics are also used at the ECE and they refer to the scoring guides or sets of expectations or criteria used to assess student level of understanding and allow them to know the expectations and what they need to do in order to learn at a higher level [17].

Conferences are short informal meetings held with individual students, or a small group of students, and it involves diagnostic listening, questioning, and responding. Portfolios refer to files or binders which hold and or present sample collection of individual student's best work or to demonstrate the students' educational growth over a given time [18], [17], [19]. All these tools are supposed to be employed at the early childhood settings to assess different attributes or treats. These methods may produce similar results if not the same. The selection of an assessment method depends on what to assess, how to assess and why assessed. Choosing assessment strategies and tools require that teachers consider the range of classroom situations that students will experience. A variety of tools and resources may be used to achieve a similar goal.

\section{Experiences ECE Teachers have as they Use the Assessment Tools}

In the educational setting, assessment can be carried out using different tools and methods. The continual usage of these tools build the experience of the teachers in using them for assessment and interpreting the assessment results they accumulate from the use of the tools. According to [19], here are some experiences teachers have as they use the assessment tools in their various classrooms. Examples are:

First, Teachers experience in choosing assessment methods appropriate for instructional decisions. Skills in choosing appropriate, useful, administratively convenient, technically adequate, and fair assessment methods are prerequisite to good use of information to support instructional decisions [19]. Teachers encounter/experience these in their daily practices. Thus, they need to be wellacquainted with the kinds of information provided by a broad range of assessment alternatives and their strengths and weaknesses. In particular, they should be familiar with criteria for evaluating and selecting assessment methods in light of instructional plans [19].

Second: Teachers experiences in developing assessment methods appropriate for instructional decisions. While teachers often use published or other external assessment tools, the bulk of the assessment information they use for decision-making comes from approaches they create and implement [19]. They include following appropriate principles for developing and using assessment methods in their teaching and avoiding common pitfalls in student assessment [19].

Third: The teacher experiences in administering, scoring and interpreting the results of both externally-produced and teacher-produced assessment methods. It is not enough that teachers are able to select and develop good assessment methods; they must also be able to apply them properly. Teachers should be skilled in administering, scoring, and interpreting results from diverse assessment methods [19]. Some of the experiences have to do with analyzing assessment results to identify pupils' strengths and errors. If they get inconsistent results, they should seek other explanations for the discrepancy or other data to attempt to resolve the uncertainty before arriving at a decision.

Fourth: Teachers experiences in using assessment results when making decisions about individual students, planning teaching, developing curriculum, and school improvement. Teachers experiences extend to using assessment results to make educational decisions at several levels: in the classroom about students, in the community about a school and a school district, and in society, generally, about the purposes and outcomes of the educational enterprise. Teachers play a vital role when participating in decision-making at each of these levels and must be able to use assessment results effectively [20].

Fifth: Teachers experiences in communicating assessment results to students, parents, other lay audiences, and other educators. Teachers must routinely report assessment results to students and to parents or guardians. In addition, they are frequently asked to report or to discuss assessment results with other educators and with diverse lay audiences. If the results are not communicated effectively, they may be misused or not used [19]. To communicate effectively with others on matters of student assessment, teachers must be able to use assessment terminology appropriately and must be able to articulate the meaning, limitations, and implications of assessment results. Furthermore, teachers experiences sometimes include being in a position that requires them to defend their own assessment procedures and their interpretations [19]. At other times, teachers may need to help the public to interpret assessment results appropriately. 
The discussions above suggests quite clearly that assessment and its application at the ECE level requires clear and deeper understanding on how to appropriately select and apply a specific tool to gather the right information and experiences one needs to exhibit particularly for the design and administration of an assessment tool and the interpretation and use of assessment results. However, there is a common knowledge as Ghanaians that since graduates from various universities of education and colleges of education have taken a semester or two courses in assessment and testing that is enough to guarantee good assessment practices at the basic school level including early childhood level.

It appears that in most cases, these premises are entirely not the case/practice. Amedahe [20] maintained that "teacher - based tests may be made of a number of factors. Notable among them are training in assessment techniques, class size and a particular school's policy in assessment standards with implications on validity and reliability of the assessment results" (p. 112-113). Again, most teachers in basic schools in Ghana do not really adhere to assessment principles. Most of the early childhood teachers in Ghana appear to be of the low academic and professional training background [21] and [22] asserted that most Ghanaian teachers had limited skills for constructing the objective and essay type tests, which are the most frequently, used assessment instruments in our schools. This is because most initial teacher training programmes do not make adequate provision for a course in assessment.

Thus, there are many problems associated with teachers' assessment practices in Ghana and the world at large. These include teachers' inadequate knowledge regarding the basic assessment concepts [23], [24], [25], limited teacher training in assessment and failure of teachers to employ and adhere to assessment and measurement guidelines they learned [26]. As a result of this, it is imperative to understand the ways in which early childhood teachers understand assessment practices, their perceptions regarding assessment tools and their experiences as they attempt to use various assessment methods to evaluate children's learning outcomes.

Although the early childhood curriculum designers prescribed an appropriate assessment practices to be used in early childhood settings in Ghana, there appears to be little or no evidence to show whether the implementers are following the prescribed practices or not. From our readings, it appears that there are relatively few studies on the entire assessment practices in our Ghanaian educational settings. Moreover, those studies that are conducted paid attention to the primary, Junior and Senior High Schools and not specifically at the early childhood settings. This paper endeavoured to bring awareness on assessment practices specifically in early childhood centres in the Kumasi metropolis of Ghana.

\section{Objectives of the Study}

The specific objectives of the study were to;

1. identify the level of understanding of ECE teachers about assessment practices in the selected ECE centres.

2. ascertain the assessment tools ECE teachers use in assessing their pupils in the selected early childhood centres.

3. explore the experiences ECE teachers have as they use the assessment tools.

\section{E. Research Questions}

1. What is the level of understanding of ECE teachers about assessment practices in the selected early childhood centres in the Kumasi Metropolis?

2. What assessment tools do ECE teachers use in assessing their pupils in the selected early childhood centres in the Kumasi Metropolis?

3. What experiences do ECE teachers have as they use the assessment tools in the selected early childhood centres in the Kumasi Metropolis?

\section{METHODOLOGY}

\section{A. Research Design}

Sequential explanatory mixed method design was employed in the study. Thus, quantitative and qualitative data were collected and analyzed sequentially with quantitative data being collected and analyzed first followed by qualitative data. The purpose of sequential explanatory mixed method design was that qualitative data was used to enrich, explain or elaborate, results gained from the quantitative approach [27]. This study had two phases: Phase one involved the collection and analysis of quantitative data. The second phase employed qualitative method to elaborate on the results from the quantitative data. The use of both forms of data allowed the researchers to generalize results from a sample to a population and to gain a deeper understanding of the phenomenon of interest [28].

\section{B. Population and Sampling Techniques}

The accessible population was the trained kindergarten teachers in early childhood centres within the Kumasi metropolis. The accessible population was 672 drawn from 298 schools selected within the metropolis (Kumasi Metro Education Directorate, 2017/2018 academic year). The sample for the study consisted of 242 kindergarten teachers selected from 149 schools. This sample was determined and calculated using [29] and [30] sampling table. Using Krejcie and Morgan sampling table, a population of 672 gave a sample of 242. Therefore, a sample size of 242 for this study was considered large enough to produce the desired results and allow for generalisation of the findings over the entire population [29], [30].

A table of random numbers was used to select the 242 sample from the accessible population of 672. With this procedure and to ensure fair representation of each respondent, a three-digit number frame was created since the accessible population (672) was a three-digit number. All the respondents were given three-digit numbers starting with 001 to 672 . A starting point was then selected from the table of random numbers and three-digit number frame was created and selected from the starting point until we got the sample size of 242 .

The Phase 2 saw to the selection of participants for the interview. After analysing the quantitative data, the researchers identified some areas that needed explanation and clarification [27]. Six of the respondents who took part in the study were randomly identified and those who agreed to be contacted were purposefully interviewed. Their views constituted the qualitative data. This was to supplement the information provided in the quantitative information gathered. To ensure anonymity, each teacher was given a pseudonym [31]. 


\section{Research Instruments}

Questionnaire was one of the tools used for this study as it supplied the researchers with quantifiable data that were available for statistical analyses [32]. Thus, the basic objective of the questionnaire was to obtain facts and opinions about assessment practices from people who were informed on the underlining issues of the study. The questionnaire was close-ended type developed on four-point Likert scale ranging from "Strongly agree to Strongly Disagree". A structured interview was also used to collect data on teachers' view on assessment practices to support the questionnaire responses, as it was the most appropriate tool for the data [33], [34]. The interview helped researchers to gain insight into the phenomenon under study.

\section{Data Analysis and Processing}

The quantitative data gathered from the field were analysed using descriptive statistics (means and standard deviation). Responses to the various items in the questionnaires were tabulated and statistically analysed. In the analysis, the mean provided the summary of the responses and the standard deviation indicated whether the responses were clustered to the mean score or dispersed from it. Also, in the analysis, standard deviation ranged from 0 to 1 . Where the standard deviation was relatively small (within 0), the teachers' responses were believed to be homogeneous (similar responses). On the other hand, where the standard deviation was relatively large (within 1), the teachers' responses were believed to be heterogeneous (dissimilar responses).

A mean more than 3.0 indicated teachers' positive perception while a mean of 2.99 and below indicated a negative perception towards assessment practice. Kurtosis values were used to determine the normality and skewness of the responses. The data from the interviews were transcribed and analysed thematically. With this procedure, common trends that extended throughout the entire interview were identified. The tape-recorded interviews were transcribed, after several readings by the researchers. The transcribed interviews were then summarized; keeping in mind the possibility of multiple themes that might exist in a set of interviews.

\section{RESULTS AND DISCUSSION}

To gather evidences on knowledge and assessment practices, the respondents were required to rate their responses using Strongly Disagree (SD), Disagree (D), Agree (A) and Strongly Agree (SA). Using means, the scales were scored as $(\mathrm{SD}=1, \mathrm{D}=2, \mathrm{~A}=3, \mathrm{SA}=4)$. A criterion value of 2.50 was established for the scale. To obtain the criterion value $(\mathrm{CV}=2.50)$, the scores were added together and divided by the number scale $(4+3+2+1=10 / 4=2.50)$. To understand the mean scores, items/statements that scored a mean of 0.00 to 2.49 were regarded as low and those that scored a mean from 2.50 to 4.00 were regarded as high knowledge and assessment practices among the teachers.

\section{RQ1: What is the level of understanding of ECE teachers about assessment practices?}

This research question was intended to assess the level of understanding of the teachers of the selected school about their assessment practices. The responses are in Table 1.
From Table I, and starting with the kurtosis values, the results show that the variables (indicates some knowledge of teachers on types of assessment) follow a normal distribution. This is based on the fact that the kurtosis values in Table 1 were within the acceptable limit for normal distribution of \pm 2 as advised by [35], [36] signifying that the data was normal.

\section{TABLE I: LEVEL OF UNDERSTANDING OF ECE TEACHERS ABOUT} ASSESSMENT PRACTICES

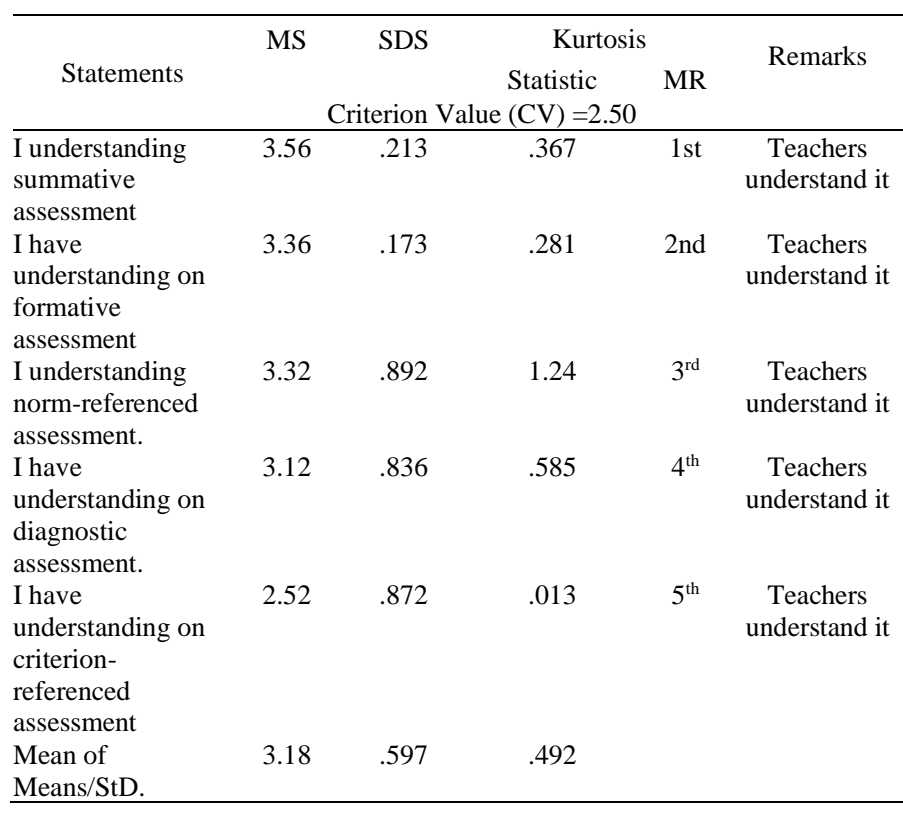

Focusing on the mean values in Table I, the results show that, to a large extent, most teachers in the early childhood centres in the selected schools have knowledge of some types of assessment available to them. This was apparent after the obtained average score was found to be larger than the $\mathrm{CV}$ of $2.50(\underline{M}=3.18, \underline{S D}=.597, \underline{K S}=.492, \underline{n}=232)$. However, the mean values varied in magnitude suggesting that they have knowledge on some of assessment types and some were employed more by the teachers at the ECE centres in the Kumasi Metropolis than others.

For example, the table shows that most of the selected ECE teachers measure pupils' achievements at the end of instruction (Summative Assessment) $(\underline{M}=3.56, \underline{S D}=.213$, $\underline{K S}=.367, \underline{n}=232$ ). By inferences, since it is mandatory for every teacher to measure pupils' achievements at the end of instruction, the teacher is compelled to employ it and this could account for the results. Again, the table suggests that teachers had understanding in formative assessment and therefore assess pupils' achievements during instruction (Formative Assessment $)(\underline{M}=3.36, \underline{S D}=.173, \underline{K S}=.281$, $\underline{n}=232$ ). Reasoning from the results, it could imply that, since it is required for every teacher to measure pupils' achievement during instruction, they are somehow coerced to employ that and this could have influenced the use of that type of assessment.

In a similar result, it was found from the table that teachers compare performance of one group against another group of pupils; and teachers assess pupils' strengths, weaknesses, knowledge and skills prior to instruction. The 
positive results on the Norm-Referenced Assessment and Diagnostic Assessment could imply that the teachers might have been exposed to the recent types of assessment and as such are practicing them in their classrooms. The results on Criterion-Referenced Assessment recorded least value for the means. This indicates that teachers rarely employed this type of assessment $(\underline{M}=2.52, \underline{S D}=.872, \underline{K S}=.013, \underline{n}=232)$. This result could mean that the Criterion-Referenced Assessment is not really enforced at the early childhood level and so teachers are not encouraged to employ it.

After analyzing the responses regarding the participants understanding of the assessment practices, the researchers wanted to have in-depth knowledge about how they were using some of the assessment practices more than others and what prompted the selection of those practice. These results from the interviews appear to be in line with what was produced in the quantitative data. The interviewees clarified what they use and what prompts the usage. One of the teachers voiced thus:

I use both the formative assessment and the summative assessment, thus formative assessment is as and when you teach, you assess them whiles the summative is done at the end of the term (Respondent \#06).

Probing further on the kind of examination they give to the $\mathrm{KG}$ pupils, one of the teachers pointed out

to me, the examination depends on what they have been taught in the course of the term, and the class exercises and assignments given them previously (Respondent \#02).

In relation to the appropriateness of summative assessment, it was reported by one of the teachers that:

depending on the assessment tool you want to assess. In the KG.2 class, the pupils can use pencil and paper test (Respondent \#05).

In a related manner, Respondent \#03). expressed the views as "I understand criterion reference assessment but I don't use it often. When the participant was probed further as to why it was not often used, the response was that:

at the end of the day, I am preparing my learners for daily exercises and for the end of term. Because of this, I always use the class tests and the end of term that is why I don't use the criterion reference assessment often.

The view of (Respondent \#02) was that:

As for these types of assessment we know them because we understand them we use them as and when there is the need for us to use them.

It was found that to a large extent; most of the ECE teachers in the selected schools have some level of understanding on some types of assessment in their classes. Some of the common types were summative, formative, norm-referenced and diagnostic assessment. The findings suggest that the teachers are only exposed to the traditional types of assessment and are likely not to go beyond those types. This therefore implies that the teachers are not possibly exploring and researching beyond what they know in the classroom.

The summative assessment being the one mostly used by the respondents appear to stem from its enforcement and possible regular usage, perhaps due to the role it plays in making final decisions about pupils' placement, amongothers. The results lend ample support the work of [37] who concluded that summative assessments report the children's final results to the children themselves, their parents, and the administration. These final results become the data that are used for many purposes, including the promotion and retention of children and the evaluation of individual schools and districts. Hanna and Dettmer [38] found that summative assessment takes place after the learning has been completed and provides information and feedback that sum up the teaching and learning process.

\section{RQ2: What assessment tools do ECE teachers use in assessing their pupils in?}

Table II presents the analysis of the tools the ECE teachers were using to assess their pupils.

Dwelling on the mean values in Table 2, the results show that to an optimal level, most of the participants in the selected schools employ some tools in assessing their children. This was evident after the obtained average score was found to be a little greater than the CV of $2.50(\underline{M}=2.85$, $\underline{S D}=.518, \underline{K S}=.402, \underline{n}=232$ ). Nevertheless, the mean values presented in the ranking matter show that there was some emphasis on some of the tools than others in the schools. For instance, the table shows that most of the selected ECE teachers assess learning outcomes of their pupils through class exercise $(\underline{M}=3.82, \quad \underline{S D}=.289, \quad \underline{K S}=.445, \quad \underline{n}=232)$. Another assessment tool found was portfolios. Majority of the teachers indicated that they use building portfolios on the learning outcomes of their pupils $(\underline{M}=3.21, \underline{S D}=.254$,

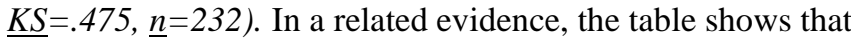
most teachers use oral questions to assess the learning outcomes of pupils $(\underline{M}=3.19, \underline{S D}=.323, \underline{K S}=.329, \underline{n}=232)$.

On the contrary, interview $(\underline{M}=2.42, \underline{S D}=.343, \underline{K S}=.134$, $\underline{n}=232)$ and class test, $(\underline{M}=2.39, \underline{S D}=.534, \underline{K S}=.452, \underline{n}=232)$ checklist, and project were found not to be tools teachers used in assessing their pupils. 
TABLE II: ASSESSMENT TOOLS ECE TEACHERS USE IN ASSESSING THEIR PUPILS

\begin{tabular}{|c|c|c|c|c|}
\hline \multirow{3}{*}{ Statements } & MS & SDS & \multicolumn{2}{|c|}{ Kurtosis } \\
\hline & & & tatistic & MR \\
\hline & \multicolumn{4}{|c|}{ Criterion Value $(\mathrm{CV})=2.50$} \\
\hline $\begin{array}{l}\text { I assess learning outcomes of } \\
\text { pupils through class exercise }\end{array}$ & 3.82 & .289 & .445 & $1^{\mathrm{st}}$ \\
\hline $\begin{array}{l}\text { I use building portfolios on the } \\
\text { learning outcomes of pupils }\end{array}$ & 3.21 & .254 & .475 & $2^{\text {nd }}$ \\
\hline $\begin{array}{l}\text { I use oral questions to assess the } \\
\text { learning outcomes of pupils }\end{array}$ & 3.19 & .323 & .329 & $3^{\text {rd }}$ \\
\hline $\begin{array}{l}\text { I use observation of learning } \\
\text { outcomes }\end{array}$ & 3.03 & .232 & .334 & $4^{\text {th }}$ \\
\hline $\begin{array}{l}\text { I assess learning outcomes of } \\
\text { pupils through performance of } \\
\text { task }\end{array}$ & 2.82 & .923 & .397 & $5^{\text {th }}$ \\
\hline $\begin{array}{l}\text { I use testing (pencil- and -paper } \\
\text { test) }\end{array}$ & 2.61 & .234 & .577 & 6th \\
\hline $\begin{array}{l}\text { I interview pupils to assess their } \\
\text { learning outcomes }\end{array}$ & 2.42 & .343 & .134 & $7^{\text {th }}$ \\
\hline $\begin{array}{l}\text { I use class test as a tool for } \\
\text { assessing pupils }\end{array}$ & 2.39 & .534 & .452 & $8^{\text {th }}$ \\
\hline $\begin{array}{l}\text { I assess learners learning } \\
\text { outcomes through checklist }\end{array}$ & 2.31 & .612 & .464 & $9^{\text {th }}$ \\
\hline $\begin{array}{l}\text { I assess learning outcomes of } \\
\text { pupils through Project Work }\end{array}$ & 2.12 & 630 & .473 & $10^{\text {th }}$ \\
\hline Mean of Means/StD. & 2.85 & .518 & .402 & \\
\hline
\end{tabular}

The responses from the quantitative data as expressed in Table 2 prompted the researchers to find out more about why some of the assessment tools scored below the average of $\mathrm{CV}$ 2.50 and others were above.

The interviewees came out with view on the assessment tools they use in their classroom to assess their pupils. To support the figures, one of the teachers espoused this claim:

In my KG. 2 class, most of the assessment tools I use are rating scale, observation, interview and pencil-and-paper test. But, in all the rating scale is the most appropriate (Respondent \#03).

To find why the rating scale the most appropriate to be used by the teachers, one of the teachers said:

oh yes, it is. You know why? The reason is that

the rating scale assesses them holistically, thus

bringing out the potentials in the pupils (Respondent \#05).

On the issue of project work, the results varied from the quantitative results...It was reported by one of the teachers that:

of course, we use project work. The pupils are given project work depending on the lesson/topic treated (Respondent \#04).

Contrary to what Respondent 04 said, Respondent 02's experience was that:

I don't really know the project I should give them. In fact, I think that the project work is for people who are at the higher level like the University. They are those who write project work that is why I don't use it in assessing my learners at this level.

Respondent \#01's situation was that:

I have to be sincere, as for the checklists I don't use it. I am not too familiar. I am not familiar because I don't know the things I should check when I am using that one to assess the learners. I think that if they are doing class exercises that is it so there is no need to use the checklist.
It was again found that most of the teachers use assessment tools in assessing their pupils in the selected centres in the Metropolis. Some of the commonly found tools were class exercise, portfolios building, oral questions, teachers' observation and performance of task.

The responses seem to support evidence in the literature. For example, [18] says that these tools are a great way to document student behaviours and academic progress over time. They include a teacher taking brief notes on a student's interactions within the classroom with subject matter and peers, keeping an eye on learners' activities and examining strengths and weaknesses. Hattie and Anderman [39] asserted that these assessment tools are to keep records of student behaviours, skills, and attitudes in the classroom that provide cumulative information regarding progress, skills acquired, and directions for further instruction. This clearly shows that the selection of an assessment method should be informed by what is to be assess, how to assess and why assessment [18]. Thus, choosing assessment strategies and tools require should that teachers to consider a range of classroom situations that students will experience. Consequently, a diversity of tools and resources may be used to achieve a similar goal [19].

\section{RQ3: What experiences do ECE teachers have as they use the assessment tool in the selected early childhood centres in the Kumasi Metropolis?}

Table III presents results on the experiences ECE teachers have as they use the assessment tools in the selected early childhood centres.

In understanding the results, the mean values were used to compare the Criterion Value (CV) of 2.50. In the comparison, it was evident that the obtained average score was found to be slightly greater than the Criterion Value (CV) of 2.50 showing that on the average, most of the teachers have some experience of assessment practices $(\underline{M}=2.83, \underline{S D}=.490$, $\underline{K S}=.374, \underline{n}=232$ ). The table shows that most of the selected early childhood centres in the Kumasi Metropolis have acquired the experience that classroom assessments is to determine whether pupils have mastered the learning objectives $(M=3.81, \underline{S D}=.254, \underline{K S}=.564, \underline{n}=232)$. On the other side, it was found that most teachers do not really have experience that for each child, they have to use more than one mode of assessment $(\underline{M}=2.37, \underline{S D}=.712, \underline{K S}=.473, \underline{n}=232)$.

The participating ECE teachers shared their experiences with the researchers through their responses in Table 3. After analyzing the data, the researchers probed further, through interview, to have clarification on why most of the respondents were not, for example, using multiple assessment modes to assess their learners and why they needed more training on assessment. Whether they were not trained at all or what might have accounted for the need for more training in assessment. Varying views emanated from the interview. Some directly complementing the quantitative responses while others giving more explanation to the responses. 
TABLE III: ECE TEACHERS EXPERIENCES OF THE USE OF ASSESSMENT TOOLS IN THE SELECTED ECE CENTRES

\begin{tabular}{|c|c|c|c|c|}
\hline \multirow{3}{*}{ Statement } & \multirow[t]{2}{*}{ MS } & \multirow[t]{2}{*}{ SDS } & \multicolumn{2}{|c|}{ Kurtosis } \\
\hline & & & tatisti & MR \\
\hline & \multicolumn{4}{|c|}{ Criterion Value $(\mathrm{CV})=2.50$} \\
\hline $\begin{array}{l}\text { Assessment has given me the } \\
\text { experience to determine whether pupils } \\
\text { have mastered the learning objectives. }\end{array}$ & 3.81 & .254 & .564 & $1^{\text {st }}$ \\
\hline $\begin{array}{l}\text { Assessment training I received was } \\
\text { adequate. }\end{array}$ & 3.69 & .233 & .453 & $2^{\text {nd }}$ \\
\hline $\begin{array}{l}\text { I consider grades as rewards for good } \\
\text { work. }\end{array}$ & 3.67 & .932 & .345 & $3^{\text {rd }}$ \\
\hline $\begin{array}{l}\text { Assessment has given me the } \\
\text { experience to determine the } \\
\text { effectiveness of my instruction. }\end{array}$ & 3.23 & .565 & .475 & $4^{\text {th }}$ \\
\hline $\begin{array}{l}\text { Tests help me to focus on the } \\
\text { skills/knowledge needed by my pupils. }\end{array}$ & 3.21 & .394 & .329 & $5^{\text {th }}$ \\
\hline $\begin{array}{l}\text { I develop assessment that confirms what } \\
\text { students know and can do best. }\end{array}$ & 3.19 & .564 & .452 & $6^{\text {th }}$ \\
\hline $\begin{array}{l}\text { I am able to give appropriate feedback } \\
\text { to learners due to my experience in } \\
\text { assessment }\end{array}$ & 3.12 & .232 & .334 & $7^{\text {th }}$ \\
\hline $\begin{array}{l}\text { Giving individualized comments for } \\
\text { pupils' learning is more important than } \\
\text { giving grades. }\end{array}$ & 2.42 & .331 & .144 & $8^{\text {th }}$ \\
\hline $\begin{array}{l}\text { To really understand each child, I use } \\
\text { more than one mode of assessment. }\end{array}$ & 2.37 & .712 & .473 & $9^{\text {th }}$ \\
\hline
\end{tabular}

To complement the results from the questionnaire, the interview data suggest a fair experience of the teachers on the use of assessment. One of the teachers had this to share:

Assessment is an everyday practice. As and

when you teach, the teacher assesses

him/herself as well as the children to know

whether the method is appropriate. The

different forms of assessment (both

formative and summative are used)

(Respondent \#01).

One of the teachers pointed out that:

Assessment is done for improvement and

innovation. As a matter of fact, the pupils'

assessment training I received in the course

of my study was adequate. This has really

helped me to know how best to go about my

assessment in the classroom. (Respondent \#04).

To ascertain how they normally use texts in textbooks

to assess children, it was recorded that:

Contingent on the content whether it is

developmentally appropriate for them and

depending on the level of pupils as well

(Respondent \#06).

On how they grade the pupils. It was revealed from the interview responses that:

The pupils are not scored in our marking

rather you give comments such as good, very

good etc (Respondent \#05).

A Participants also expressed their views in respect of their experiences and shared some instances of their situations in the classrooms. For example,

As for the assessment practices I know them and the tools but sometimes the materials I have in the classroom limit me to use them (Respondent \#02).

The content of the assessment I learnt during my training was not too much to give me much confidence in using them. At some point during the training, we had to prepare and write to pass the examination. Also, from the time I studied those tools and now it has been long so there are some of them that I have forgotten (Respondent \#03).

A participant appeared to have different view regarding what these respondents have said. The experience was that: it is fun learning these tools during college and having to practice them finally in the classroom. When I am using the tools, they always remind me of the time I was learning them. They are real opportunity to practice what I learnt during my training (Respondent \#06).

Furthermore, it was evident that on the average the respondents had experiences as to their use of assessment tools in the selected early childhood centres in the Kumasi Metropolis. Reflecting on the results, it is noteworthy, especially in this contemporary era, that teachers are not expected to be striving on average understanding of assessment. This could have a negative structural effect on the pupils' performance.

The criterion value being slightly greater 2.50 and suggesting that most of the teachers' response is where in terms of experience is arguably appropriate. Teachers need to be well-acquainted with the kinds of information provided by a broad range of assessment alternatives and their strengths and weaknesses. They should be familiar with criteria for evaluating and selecting assessment methods in light of instructional plans [19]. For example, the response suggesting that the teachers provide feedback to the learners would enable the learners to be informed of the strengths and weaknesses so as to take appropriate steps to address them.

\section{CONCLUSION}

The study has been able to provide empirical evidence about early childhood teacher's practices of assessment in the schools in the Kumasi Metropolis. The findings show that the teachers had a greater understanding of early childhood assessment practices and that their responses were quite homogeneous. The findings suggest that the teachers were more comfortable to implement assessment they are familiar with. Therefore, it is important for teachers to understand these assessment practices quite clearly to be able to effectively implement them in their classrooms.

The study has also shown that some of the assessment tools were used more frequently and possibly more effectively than others, arguably due to its enforcement. This implies that the teachers on the field should be encouraged on the assessment practices so they can continuously use them. As the findings suggests, some of the teachers had forgotten some of the assessment tools they learnt during their training. This gives an impression that it is important for ongoing professional development regarding these assessment tools and their use to ensure their constant and effective implementation.

Regarding the experiences teachers have about the use of the assessment tools, the findings suggest positive experience except that the participating teachers could not use multiple assessment tools to assess the learners. What can happen as a result is that the teachers may not get comprehensive information about their learners as they possibly use only one source of assessment tool. This has the potency of wrong interpretation and subsequently arriving at the wrong conclusion. 


\section{RECOMMENDATIONS}

Based on the findings therefore, it is recommended that:

1. Teacher Education Division within the Kumasi Metropolis should frequently organise refresher courses on modern trends in assessment to keep and maintain the knowledge base and skills of the teachers in assessment practices.

2. Teachers should also be sensitized by Teacher Education Division of the Ministry of Education on regular basis on the importance of their assessment practices to effectively practicalize the assessment done on pupils. For instance, in building portfolio for pupils, teachers must not only keep the work that the children have performed better but rather include all their works to enable their parents that are invited for Parent Teacher Interaction (PTI) to be well informed on the progression and or retrogression of their children.

\section{REFERENCES}

[1] D. D. Dixson \& F. C. Worrell. "Formative and summative assessment in the classroom", Theory into practice, 2016, 55(2), pp. 153-159.

[2] P. W. Airasian. Classroom assessment: Concepts and applications. New York: McGraw-Hill. 2011

[3] C. DeLuca, A. Coombs \& D. LaPointe-McEwan. "Assessment mindset: Exploring the relationship between teacher mindset and approaches to classroom assessment", Studies in Educational Evaluation, 2019, 61, pp. 159-169.

[4] J. H. McMillan. "Section discussion: Student perceptions of assessment", Handbook of human and social conditions in assessment, 2016, pp. 221-243.

[5] C. McLachlan, M. Fleer \& S. Edwards. Early childhood curriculum: Planning, assessment and implementation. Cambridge University Press. 2018

[6] M. Heritage. Formative Assessment: Making it happen in the classroom. Thousand Oaks, CA: Corwin Press 2019

[7] K. Asare. "Exploring the kindergarten teachers' assessment practices in Ghana", Assessment, 2015. 5(8).

[8] Anane \& Y. M. Anhwere. "Assessment in preschools in Ghana: Issues and challenges", Journal of Education Development and Practice, 2013, 4(22), pp. 24-29.

[9] C. Chester \& S. M. Quilter. "Inservice teachers' perceptions of education assessment", Journal for Research in Mathematics Education, 1998, 33(2), pp. 210-236.

[10] M. Rahman. "Exploring science teachers' perception of classroom assessment in secondary schools of Bangladesh", European Journal of Education Studies, 2018, 4(9), pp. 139-160.

[11] C. M. Müller, V. Hofmann, T. Begert \& A. H. Cillessen. "Peer influence on disruptive classroom behavior depends on teachers' instructional practice", Journal of applied developmental psychology, 2018, 56, pp. 99-108

[12] B. B. Levin. "The development of teachers' beliefs", International handbook of research on teachers' beliefs, 2015, 1, pp. 48-65.

[13] A. Yates. Economics and accounting teachers' beliefs about schoolbased assessment, the summative and formative tension: A mixed method study. 2018.

[14] A. Azis. "Conception and practices of assessment: A case of teachers representing improvement conception", TEFLIN Journal, 2015, 26(2), pp. 129-154

[15] N. Barnes, H. Fives \& C. M. Dacey. "Teachers' beliefs about assessment". In H. Fives \& M. Gill (eds.), International handbook of research on teachers' beliefs. NY: Routledge. 2015, pp. 284-300.

[16] A. Ghaicha. "Theoretical Framework for Educational Assessment: A Synoptic Review", Journal of Education and Practice, 2016, 7(24), pp. 212-231.

[17] M. Tobajas, C. B. Molina, A. Quintanilla N. Alonso-Morales \& J. A Casas. "Development and application of scoring rubrics for evaluating students' competencies and learning outcomes in Chemical Engineering experimental courses. Education for Chemical" Engineers 2019, 26, pp. 80-88.
[18] N. Hempeck. Methods for documenting student progress: Strategie for Assessing and Keeping Records in the Classroom: 2009. Retrieved from http://www.Suite101.Com/profile.cfm

[19] A. J. Nitko \& S. M. Brookhart. Educational assessment of student. Englewood Cliffs. NJ: Merrill Prentice Hall. 2007.

[20] F. K. Amedahe. Continuous assessment. Unpublished paper, University of Cape Coast, Ghana. 2000

[21] C. Cobbold \& P. Boateng. "Exploring the instructional practices efficacy beliefs of Kindergarten teachers in the Kumasi Metropolis of Ghana", Journal of Education Development and Practice, 2015 5(6), pp. 173-187.

[22] E. Sasu. Testing practices of secondary schools in the Central Region of Ghana. Unpublished Master's thesis, University of Cape Coast, Cape Coast, Ghana. 2017.

[23] Y. Xu \& G. T. Brown. "Teacher assessment literacy in practice: A reconceptualization", Teaching and Teacher Education, 2016 58, pp. 149-162.

[24] C. Deluca, D. Lapointe-Mcewan, \& U. Luhanga. "Teacher assessment literacy: A review of international standards and measures", Educational Assessment, Evaluation and Accountability, $201628(3)$, pp. $251-272$

[25] R. J. Stiggins. Assessment crisis: The absence of assessment for learning. Phi Delta Kappa. (2005)8 (10), 758-765.

[26] M. Murukutla. "The Effects of Background, Classroom Assessment Competence, Self-efficacy, and Self-perceived Assessment Skills on Classroom Assessment Practices of Teachers in India". Doctoral dissertation, University of Nevada, Las Vegas 2019

[27] J. W. Creswell \& J. D. Creswell. Research design: Qualitative, quantitative, and mixed methods approaches. Sage publications, 2017.

[28] M. L. Patten \& M. Newhart. Understanding research methods: An overview of the essentials. Taylor \& Francis. 2017

[29] R. V. Krejcie \& D. W. Morgan. "Determining sample size for research activities" Educational and Psychological Measurement 1970, 30 (3), pp. 607-610

[30] H. Ahmad \& H. Halim. "Determining Sample Size for Research Activities", Selangor Business Review, 2017, 2(1), pp. 20-34.

[31] J. W. Creswell \& Clark, V. L. P. Designing and conducting mixed methods research. Sage publications. 2017

[32] S. A. McLeod. Questionnaire: definition, examples, design and types. Simply Psychology. https://www.simplypsychology.org/questionnaires.html.

[33] R. Kumar. Research methodology: A step-by-step guide for beginners. Sage. 2018

[34] J. Harding. Qualitative data analysis: From start to finish. SAGE Publications 2018

[35] D. George \&, M. Mallery. SPSS for windows step by step: A simple guide and reference, 17.0 update (11 ${ }^{\text {th }}$ ed.). 2011, BostonPearson.

[36] M. A. Pett. Nonparametric statistics for health care research: Statistics for small samples and unusual distributions. Sage Publications, 2015.

[37] K. Burke. Balanced assessment: From formative to summative. Solution Tree Press 2010

[38] G. S. Hanna \& P. A. Dettmer. Assessment for effective teaching. Using context-adaptive planning. Boston, MA: Pearson A \& B. 2004

[39] J. Hattie \& E. M. Anderman. Visible Learning Guide to Student Achievement: Schools Edition. New York: Routledge. 2019

S. Oppong Frimpong is an experienced university teacher with more than a decade teaching experience at a higher institution. Oppong Frimpong was born in Ashanti Region of Ghana. He holds Doctor of Philosophy (in early childhood education) from University of Aberdeen in Scotland, UK and completed in 2017. Oppong Frimpong also holds Master of Philosophy (in educational psychology) from University of Cape Coast in Ghana and completed in 2005.

He has a number of publications to his credit. Some of them have been listed below:

Oppong Frimpong, S. (2020). Assessing the quality of ECE teachers in Ghana: Juxtaposing theory to practice. European Journal of Education Studies. Volume 7 Issue 12 |. Doi.org/10.46827/ejes.v7i12.3505

Oppong Frimpong, S. \& Osei, D. (2020) . Socio-emotional development of the kindergarten pupil: the role of assessment in the Kumas Metropolis, Ghana. European Journal of Education Studies. Volume 7 Issue 12 | Doi.org/10.46827/ejes.v7i12.3505 
Oppong Frimpong, S. (2019). The classroom physical environment as a "third teacher" for an early childhood education provision in the Ga-West Municipality of Ghana. International Journal of Social Sciences, 4(3), 1339-1360.

$\mathrm{He}$ is a researcher interested in child growth and development, observation and assessment of the young child, interaction in Early childhood Education, creating a developmentally appropriate environment for Early childhood Education provision and issues on child safety and wellbeing at the early childhood centre. Oppong Frimpong is currently a Senior Lecturer with the Department of Early Childhood Education in the University of Education, Winneba in Ghana.

Dr. Samuel is a member of University Teachers Association of Ghana (University of Education, Winneba Branch) and a member of Ghana Psychological Council. He has held numerous positions and served on a number of committees. Positions held include:

Acting Head of Department, Department of Early Childhood Education, University of Education, Winneba; Faculty of Educational Studies (FES) representative on the University of Education, Winneba's Publications Board and currently the Co-ordinator for Supported Teaching in Schools for University of Education, Winneba and all the Affiliate Institutions, including Colleges of Education for University of Education, Winneba in Ghana. Some of the committees served on include being a Member of the Academic Board, University of Education, Winneba; Member of the National Team writing the Course Manual for Bachelor's Degree in the Colleges of Education (Early Grade Specialism) in Ghana and a Member of the National Team writing the Curriculum for Bachelor's Degree in the Colleges of Education (Early Grade Specialism.

D. Osei was born in Ashanti Region of Ghana. She holds Master of Philosophy (in early childhood education) from University of Education, Winneba, Ghana. She completed in 2019. Osei also has Bachelor of Education (in early childhood education) from the same university completing in 2011 .

As a young researcher, Ms Dorigen has a publication to her credit. Thus;

Frimpon, Oppong Frimpong, S. \& Osei, D. (2020). Socio-emotional development of the kindergarten pupil: the role of assessment in the Kumasi Metropolis, Ghana. European Journal of Education Studies. Volume 7 | Issue 12 | Doi.org/10.46827/ejes.v7i12.3505

She is a young researcher with particular research interest in teacher pedagogical activities, teacher classroom management approaches, assessment of teacher instructional strategies and developmentally appropriate early childhood classroom environment. She is a trained early childhood educator. She is currently a Lecturer at Bia Lamplighter College of Education in Ghana. 